\title{
Comparison of the Effects of Betamethasone and L-Carnitine on Dipalmitoylphosphatidylcholine Content and Phosphatidylcholine Species Composition in Fetal Rat Lungs
}

\author{
ALFRED LOHNINGER, PETER KRIEGLSTEINER, ALEXEJ NIKIFOROV, WOLFGANG ERHARDT, \\ MANFRED SPECKER, GERHARD MARTIN, AND ERICH KAISER \\ Institute of Medical Chemistry and the Institute of Organic Chemistry, Department of Mass Spectrometry, \\ University of Vienna, Vienna, Austria and the Department of Obstetrics and Gynecology and the Institute of \\ Experimental Surgery, Technical University of Munich, Munich, Federal Republic of Germany
}

\begin{abstract}
Antepartum administration of L-carnitine to pregnant rats results in an increase of both total phospholipid (80 $\pm 11 \mathrm{mg} / \mathrm{g}$ dry weight (dw); mean \pm SD) and dipalmitoylphosphatidylcholine (DPPC) content (7.7 \pm 2.1 $\mathrm{mg} / \mathrm{g} \mathrm{dw}$ ) in fetal lungs as compared to controls (72 \pm 10 and $7.0 \pm 2.5 \mathrm{mg} / \mathrm{g} \mathrm{dw}$, respectively). On the other hand, no effect of $L$-carnitine could be demonstrated on the DPPC portion in the total phosphatidylcholine $(P C)$ or on the portion of palmitic acid in the $\mathrm{PC}$ fatty acids.

Betamethasone elevated the DPPC content in fetal lungs (8.1 \pm 2.0 versus $7.0 \pm 2.5 \mathrm{mg} / \mathrm{g} \mathrm{dw}$ in the controls), while total phospholipid content remained unaffected $(71 \pm 19$ versus $72 \pm 10 \mathrm{mg} / \mathrm{g} \mathrm{dw}$ ). The portion of DPPC in the PC species increased significantly $(p<0.01)$ from $27.6 \pm 4.5$ in the fetal lungs of the control group to $34.2 \pm 3.3$ in the lungs of the betamethasone-treated group, while the palmitic acid portion in the PC fatty acids was nearly unchanged (45.9 \pm 3.2 versus $43.9 \pm 2.6$ in the controls). Further, after betamethasone treatment, a significant diminution $(p<0.01)$ of the monoenic PC 32 species (palmitoyl-palmitoleyl PC and palmitoleyl-palmitoyl-PC) and the PC 34 species (consisting primarily of palmitoyl-oleoylPC) could be demonstrated both in absolute and relative terms. This is in agreement with a significant reduction of the portions of palmitoleic $(p<0.01)$ and oleic $(p<0.05)$ acids in the total PC fatty acids. The findings suggest two different mechanisms of DPPC elevation in fetal rat lungs for L-carnitine and betamethasone. (Pediatr Res 18:12461252, 1984)
\end{abstract}

\section{Abbreviations}

DPPC, dipalmitoylphosphatidylcholine

PC, phosphatidylcholine

PC-30, total carbon atoms in acyl radicals is $\mathbf{3 0}$

PC-32, total carbon atoms in acyl radicals is 32

PC-34, total carbon atoms in acyl radicals is 34

GLC $^{2}$, gas-liquid chromatography with glass capillary columns

MS, mass spectrometry

$t$-BDMS, $t$-butyldimethylsilyl

Received July 7, 1983; accepted May 18, 1984

Requests for reprints should be addressed to Alfred Lohninger, Institute of Medical Chemistry, University of Vienna, Währingerstrasse 10, A-1090 Vienna, Austria.

This work was supported by grants from the Allianz Insurance Company, Germany, and from the Hochschul-Jubiläums-Stiftung der Stadt Wien.
TMS, trimethylsilyl

16:0/16:1-PC, palmitoyl-palmitoleyl-PC

16:1/16:0-PC, palmitoleyl-palmitoyl-PC

dw, dry weight

HEPES, 4-(2-hydroxyethyl)-1-piperazineethanesulfonic acid

Acceleration of fetal pulmonary maturation processes in cases of imminent premature delivery or when progressive intrauterine damage makes premature delivery necessary is a not yet solved problem. Liggins et al. $(26,27)$ were the first to report on the acceleratory effect of maternally administered glucocorticoids on fetal lung maturation. These findings were subsequently substantiated by numerous studies on various species. A similar effect on fetal lung maturation has also been demonstrated for several other hormones: adrenocorticotropic hormone (46), thyrotropin releasing hormone (42), thyroxine $(44,52), 17 \beta$-estradiol $(39)$, and prolactin (20). Animal experiments and clinical observations suggest that $\beta$-adrenergic agonists, such as isoxsuprine (24) and hexoprenaline (28), and cholinergic agonists, such as oxotremorine (1), also promote fetal lung maturation.

The use of carnitine appears to be of special interest, since it produces no known toxic side effects $(47,51)$. Both carnitine (L3-hydroxy-4- $N$-trimethylaminobutyrate) and its acyl esters are found in living cells. Its role in the oxidation of fatty acids by mitochondria is well established (14). However, the extramitochondrial occurrence of acetylcarnitine and octanoylcarnitine transferase activities in rat liver and kidney tissue is difficult to explain solely by the fact that carnitine is involved in fatty acid oxidation (32). Numerous recent reports have suggested roles for carnitine beyond that of long chain fatty acid transport. These functions, such as the buffering of the coenzyme A pool (10), the formation of acylcarnitines involved in branched chain amino acid metabolism (21), and carnitine-mediated transfer of acetyl groups out of the mitochondria have been demonstrated (31).

In the present study, we investigated the possibility of promoting phospholipid synthesis in fetal lungs by means of maternal carnitine treatment. Further, the effects of carnitine and betamethasone on DPPC content and PC species composition in fetal rat lungs were compared.

\section{MATERIALS AAND METHODS}

We chose the following experimental model. Thirty gravid Wistar rats of stock $\mathrm{Ch}$ bb-Thom with an average weight of 300 
$\mathrm{g}$ and an expected gestation period of 23 days were randomized, divided into three groups, and treated from the 17th to the 20th day of gestation with $1 \mathrm{ml} /$ day physiologic saline (controls to equalize the trauma), or L-carnitine $(10 \mathrm{mg} / \mathrm{kg}$ in $1 \mathrm{ml}$ distilled water), or betamethasone $(0.3 \mathrm{mg} / \mathrm{kg}$ in $1 \mathrm{ml}$ distilled water), administered intraperitoneally. Delivery by cesarean section took place on the 21 st day. Laparatomy of the mother animals was performed by means of abdominal longitudinal incision. In the course of the hysterotomy, both uterine cornua were opened along their full length. The fetuses, not allowed to breath, were thoracotomized by means of parasternal incision. The fetal lungs were then grouped according to litter in order to preclude stationrelated differences.

The fetal lungs were homogenized in 40 volumes of chloroform/methanol (2:1, vol/vol) and extracted overnight under nitrogen. The tissue lipid extracts were washed using the method of Folch et al. (13), and the phospholipids were assayed by a modified version of Bartlett's method (7).

1,2-Dipalmitoyl-sn-glycero-3-phosphocholine was assayed as a diacylglycerol trimethylsilyl ether derivative by $\mathrm{GLC}^{2}$, using 1,2-dimyristoyl-sn-glycero-3-phosphocholine serving as the internal standard (29).

Aliquots of the samples were applied as bands on previously cleaned thin layer chromatographic plates. The plates were developed in a chloroform/methanol/1\% potassium chloride solution $(43: 47: 4, \mathrm{vol} / \mathrm{vol} / \mathrm{vol})$ and dried, and the 3-sn-phosphatidylcholine fraction was removed from the plates. The 1,2-diacyl$s n$-glycerols of 3-sn-phosphatidylcholine were obtained by digestion with phospholipase $C$ from Baccillus cereus. The TMS ethers of 1,2-diacyl-sn-glycerols were prepared by reaction with pyridine/hexamethyldisilazane/chlorotrimethylsilane (12:5:2, vol/ $\mathrm{vol} / \mathrm{vol})$. The $t$-BDMS ethers of diacylglycerols were prepared by the method described by Myher et al. (35) by reaction with $t$ BDMS chloride. The resulting TMS and $t$-BDMS ether solutions were used directly for subsequent $\mathrm{GLC}^{2}$ analyses. The individual diacylglycerol species were then identified by GLC $^{2}$-MS combination on the basis of $t$-BDMS derivatives (36).

PC fatty acids were determined as methyl ester derivatives by GLC ${ }^{2}$.

Carnitine assay. The tissue was flash-frozen immediately after removal. The perchloric acid extracts were used for assaying the free and short chain acylcarnitine. The carnitine esters were saponified and assayed as free carnitine by radioenzymatic means (34). By using HEPES instead of Tris buffer (11), the determination accuracy was increased.

Chemicals. Chloroform, methanol, pyridine, hexamethyldisilazane, and thin layer chromatographic plates (silica gel 60) were obtained from E. Merck (Darmstadt, F. R. G.). B. cereus-derived phospholipase $\mathrm{C}$ was prepared by Boehringer (Mannheim, F. R. G.). $t$-BDMS chloride was obtained from Petrarch Systems Inc. (Levittown, PA). Dimyristoyl-sn-glycero-3-phosphocholine was supplied by Sigma (St. Louis, MO).

Statistical comparisons between the control group and the treated groups were made using analysis of variance followed by Dunnet's $t$ test for multiple comparison.

\section{RESULTS}

Total phospholipid content. Following betamethasone treatment, no increase in phospholipid content was found in the fetal lungs as compared to the control group ( $71 \pm 19$ versus $72 \pm 10$ $\mathrm{mg} / \mathrm{g} \mathrm{dw}$; mean $\pm \mathrm{SD}$ ). By contrast, there was an increase to 80 $\pm 11 \mathrm{mg} / \mathrm{g} \mathrm{dw}$ following L-carnitine administration (Fig. 1).

Dipalmitoylphosphatidylcholine. Figure 2 shows the DPPC content of the fetal lungs in $\mathrm{mg} / \mathrm{g} \mathrm{dw}$ and the portion of DPPC in the $\mathrm{PC}$ species. Both betamethasone and $\mathrm{L}$-carnitine treatment induced a quantitative elevation of the DPPC content $(8.1 \pm 2.0$ $\mathrm{mg} / \mathrm{g} \mathrm{dw}$ in the betamethasone group; $7.7 \pm 2.1 \mathrm{mg} / \mathrm{g} \mathrm{dw}$ in the carnitine group versus $7.0 \pm 2.5 \mathrm{mg} / \mathrm{g} \mathrm{dw}$ in the control group). The portion of DPPC in the PC species exhibited a rise only in the betamethasone group $(34.2 \pm 3.3 \%)$ versus the control value

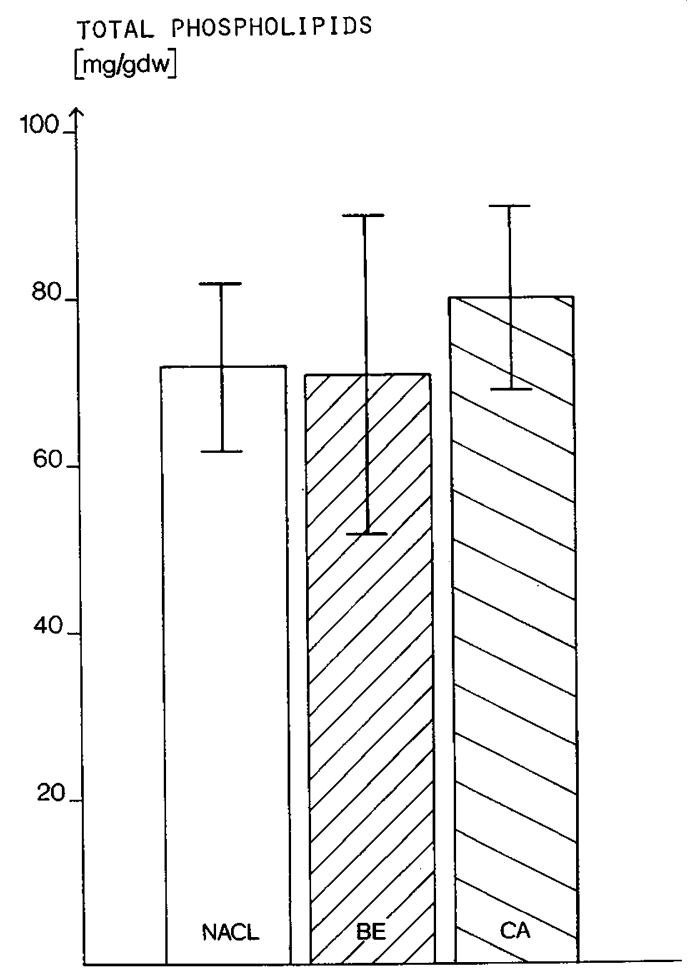

Fig. 1. Total phospholipid content in fetal rat lungs following maternal betamethasone $(B E)(72 \pm 10 \mathrm{mg} / \mathrm{g} \mathrm{dw} ; n=7)$ and L-carnitine $(C A)$ $(80 \pm 11 \mathrm{mg} / \mathrm{g} \mathrm{dw} ; n=7)$ treatment, in comparison to the control group $(N A C L)(71 \pm 19 \mathrm{mg} / \mathrm{g} \mathrm{dw} ; n=7)$. Bars indicate the mean $\pm \mathrm{SD}$ in each group.

$(27.6 \pm 4.5 \%)(p<0.01)$, whereas no response to carnitine administration was noted $(27.6 \pm 2.0 \%)$.

These findings indicate that steroid treatment leads to a selective elevation of the DPPC level (per $g \mathrm{dw}$ ) in the fetal lungs whereas the rise in the DPPC level after carnitine administration appears to be attributable to an overall enhancement of PC content in the fetal lungs.

PC-32 monoenic species. The PC-32 monoenic species can be characterized as 16:0/16:1-PC and 16:1/16:0-PC $(29,36)$. A relatively high portion of $16: 1 / 16: 0-\mathrm{PC}$ is probably characteristic for the fetal lung as compared to the adult lung, since analogous patterns have also been found in human amniotic fluid (30). and fetal sheep lungs (A. Lohninger, unpublished results). Figure $3 A$ presents the percentage portion of the 16:0/16:1-PC and Figure $3 B$ that of the $16: 1 / 16: 0$-PC in the PC species of the fetal lungs. $16: 0 / 16: 1-\mathrm{PC}$ is significantly $(p<0.01)$ lower in the steroidtreated group $(3.6 \pm 0.4 \%)$ than in the carnitine group $(4.4 \pm$ $0.4 \%)$ and the controls $(4.4 \pm 0.4 \%)$, whereas $16: 1 / 16: 0-\mathrm{PC}$ is present in higher levels in the carnitine-treated group (13.0 \pm $3.0 \%)$ than in the steroid $(10.0 \pm 1.1 \%)$ and control $(11.8 \pm$ $3.3 \%$ ) groups. These differences in PC species composition are also manifested in quantitative terms (Fig. 4). These findings were confirmed by analysis of the PC fatty acid composition.

Composition of the PC fatty acids. Table 1 shows the relative composition of the esterified fatty acids in the PC of the fetal lungs. The portion of palmitic acid was nearly unchanged in the treated groups in comparison to the control group. The administration of betamethasone resulted in a lowering of the relative portion of the monoenic fatty acids $(16: 1,18: 1)$ and to an increase in the relative portion of polyenic fatty acids $(18: 2,20: 4)$ in the esterified fatty acids of the pulmonary PC (Table 1).

In comparing the PC fatty acid profile (Table 1) with the changes in the portion of the PC-32 monoenic species in the total PC species after betamethasone treatment (Fig. 3), there is a significant percentage decrease $(p<0.01)$ of $16: 1$ in the PC fatty acids that coincides with the reduction in the 16:0/16:1-PC 
A

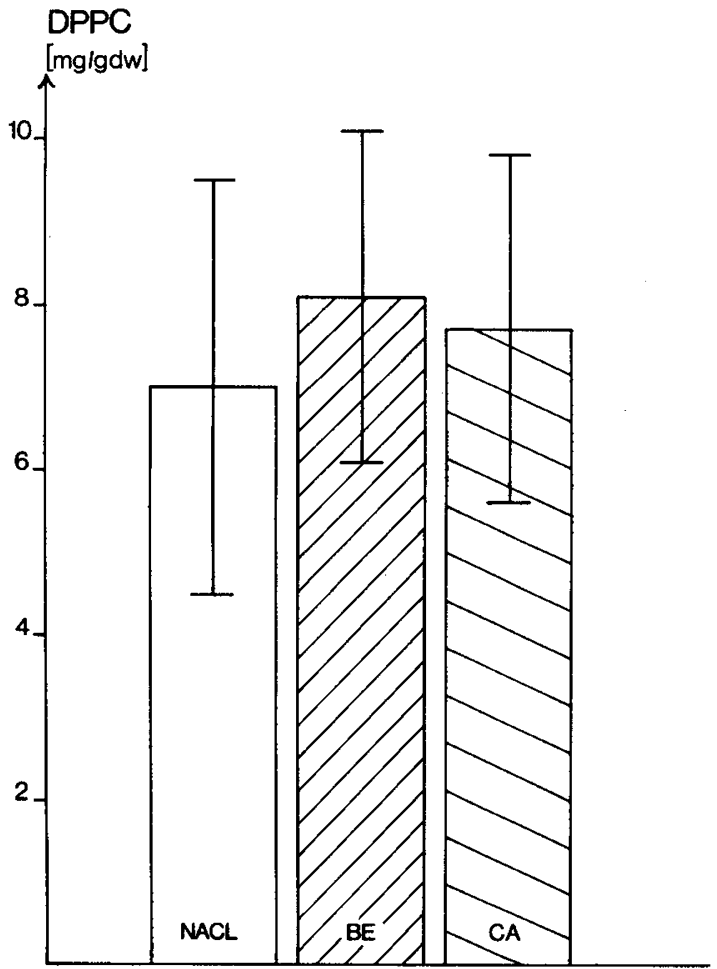

B

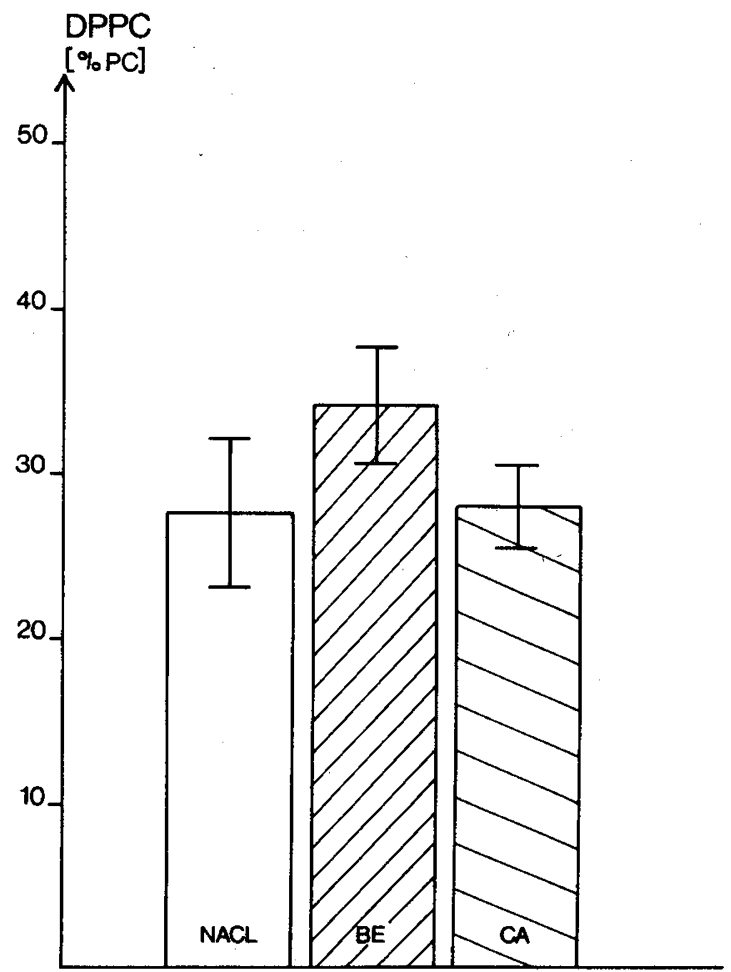

Fig. 2. DPPC content in fetal rat lungs following maternal betamethasone $(B E)$ and L-carnitine $(C A)$ treatment in comparison to the control group (NACL). A, DPPC content in $\mathrm{mg} / \mathrm{g}$ dw $(B E: 8.1 \pm 2.0, n=7 ; C A: 7.7 \pm 2.1, n=7 ; N A C L: 7.0 \pm 2.5, n=7)$. B, portion of DPPC in the fetal lung species ( $B E: 34.2 \% \pm 3.3, n=10 ; C A: 27.7 \% \pm 2.6, n=9 ; N A C L: 27.6 \% \pm 4.5, n=7)$; the $B E$ value is significantly $(p<0.01)$ higher compared to those of $N A C L$ and $C A$. Bars indicate the mean $\pm \mathrm{SD}$ in each group.
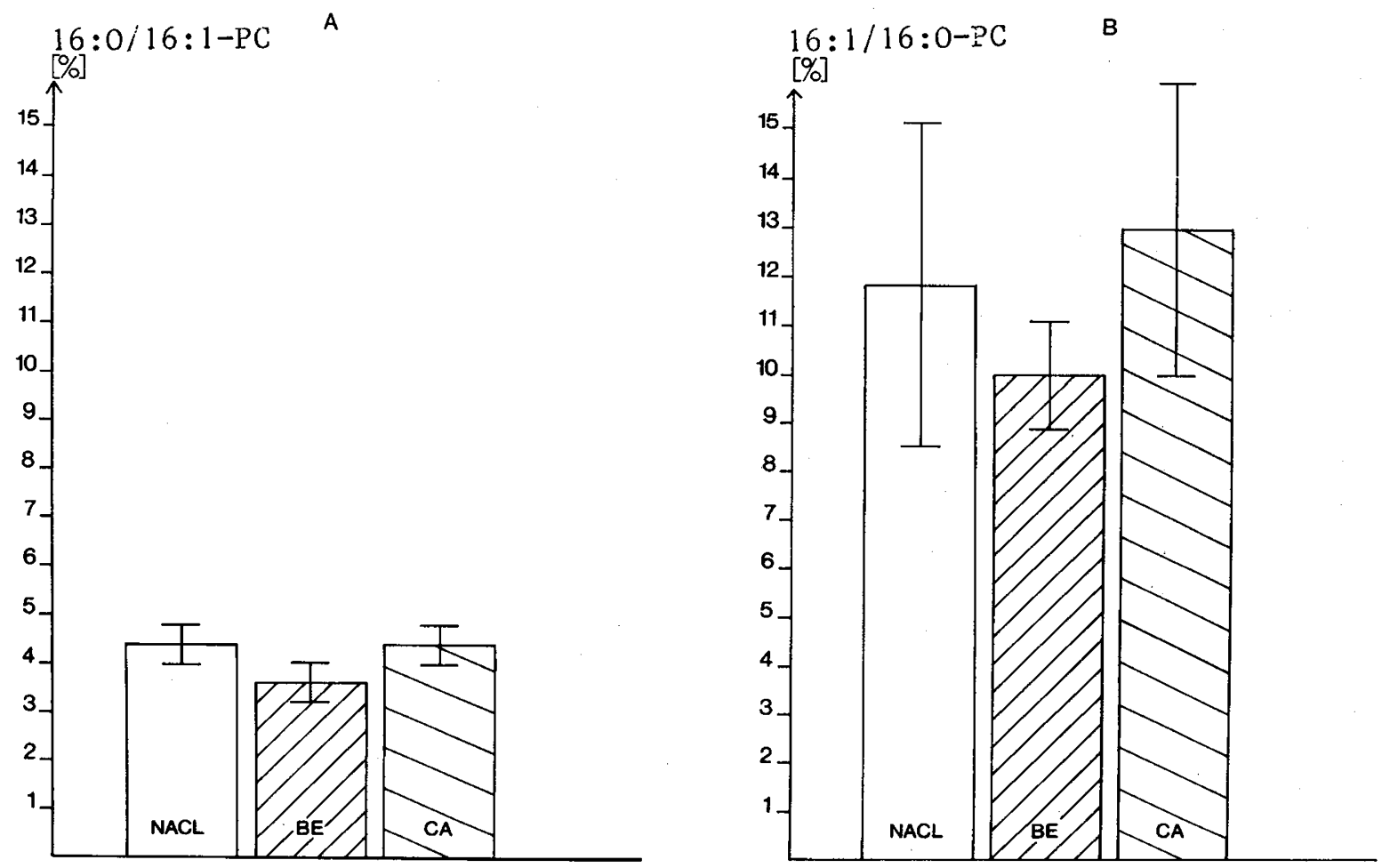

Fig. 3. Portion of the monounsaturated PC-32 (i.e. the sum of carbon atoms in the acyl radicals is 32) species in fetal rat lung PC following maternal betamethasone $(B E)$ and $\mathrm{L}$-carnitine $(C A)$ treatment in comparison to the control group $(N A C L)$. The PC-32 monoenic species can be characterized as palmitoyl-palmitoleyl-PC (16:0/16:1-PC) $(A)$ and palmitoleyl-palmitoyl-PC (16:1/16:0-PC) $(B) . A, B E(3.6 \% \pm 0.4, n=10)$ is significantly decreased $(p<0.01)$ compared to $C A(4.4 \% \pm 0.4, n=9)$ and $N A C L(4.4 \% \pm 0.4, n=7) . B, B E: 10.0 \% \pm 1.1, n=10 ; C A: 13.0 \% \pm$ $3.0, n=9 ; N A C L: 11.8 \% \pm 3.3, n=7$. Bars indicate the mean \pm SD in each group. 

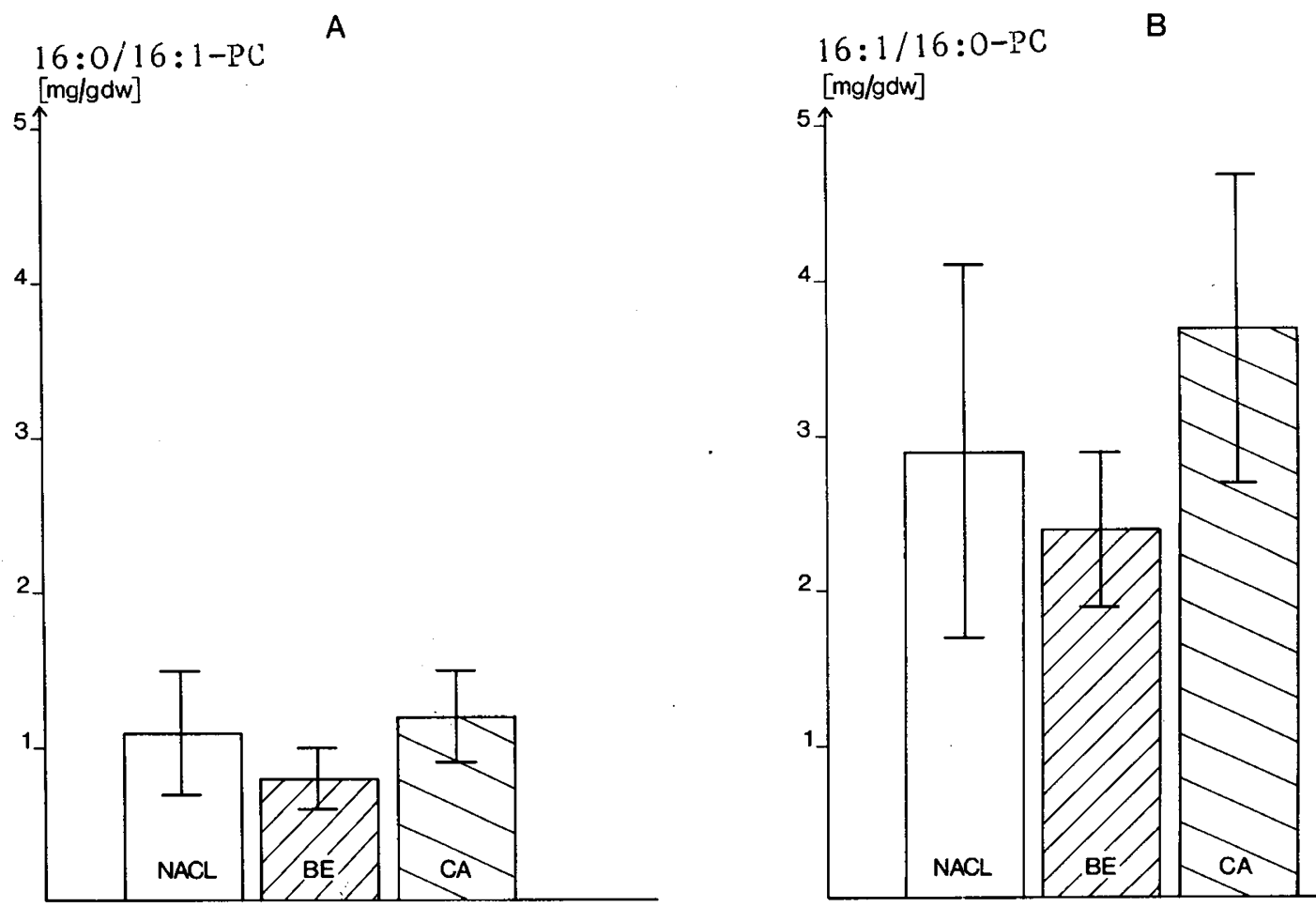

Fig. 4. Absolute content of monounsaturated PC-32 (i.e. the sum of carbon atoms in the acyl radicals is 32 ) species in $\mathrm{mg} / \mathrm{g} \mathrm{dw}$ of fetal rat lungs following maternal betamethasone $(B E)$ and L-carnitine $(C A)$ treatment in comparison to the control group $(N A C L)$. The PC-32 monoenic species can be characterized as palmitoyl-palmitoleyl-PC (16:0/16:1-PC) $(A)$ and palmitoleyl-palmitoyl-PC (16:1/16:0-PC) $(B) . A, N A C L: 1.1 \mathrm{mg} / \mathrm{g} \mathrm{dw} \pm$ $0.4(n=7) ; B E: 0.8 \pm 0.2(n=7) ;$ and $C A: 1.2 \pm 0.3(n=7) . B, N A C L: 2.9 \mathrm{mg} / \mathrm{g} \mathrm{dw} \pm 1.2(n=7) ; B E: 2.4 \pm 0.5(n=7) ;$ and $C A: 3.7 \pm 1.0(n=$ 7). There is a significant difference $(p<0.05)$ comparing the $B E$ group with the $C A$ group, in both $A$ and $B$. Bars indicate the mean \pm SD in each group.

Table 1. Relative composition of esterified PC fatty acids*

\begin{tabular}{llllllc}
\hline \multicolumn{1}{c}{ Treatment } & $16: 0$ & \multicolumn{1}{c}{$16: 1$} & $18: 0$ & $18: 1$ & $18: 2$ & $20: 4$ \\
\hline NaCl (controls) (7) & $43.9 \pm 2.6$ & $9.1 \pm 1.6$ & $8.3 \pm 1.7$ & $19.7 \pm 2.3$ & $5.5 \pm 0.7$ & $6.6 \pm 0.7$ \\
Betamethasone (11) & $45.9 \pm 3.2$ & $7.1 \pm 1.0 \dagger$ & $9.0 \pm 1.6$ & $16.9 \pm 1.9 \ddagger$ & $6.6 \pm 0.7$ & $8.5 \pm 1.9$ \\
Carnitine (10) & $44.2 \pm 1.8$ & $9.0 \pm 1.5$ & $8.8 \pm 1.1$ & $23.1 \pm 2.7$ & $4.8 \pm 0.9$ & $7.2 \pm 1.4$ \\
\hline
\end{tabular}

* Values are mean $\pm \mathrm{SD}$, with number of experiments in parentheses. 16:0, palmitic acid; 16:1, palmitoleic acid; 18:0, stearic acid; 18:1, oleic acid; $18: 2$, linoleic acid; 20:4, arachidonic acid.

$\dagger$ Significantly lower $(p<0.05)$ compared to the control and carnitine groups.

$\ddagger$ Significantly lower $(p<0.01)$ compared to the control and carnitine groups.

Table 2. PC species (percentage of total PC)*

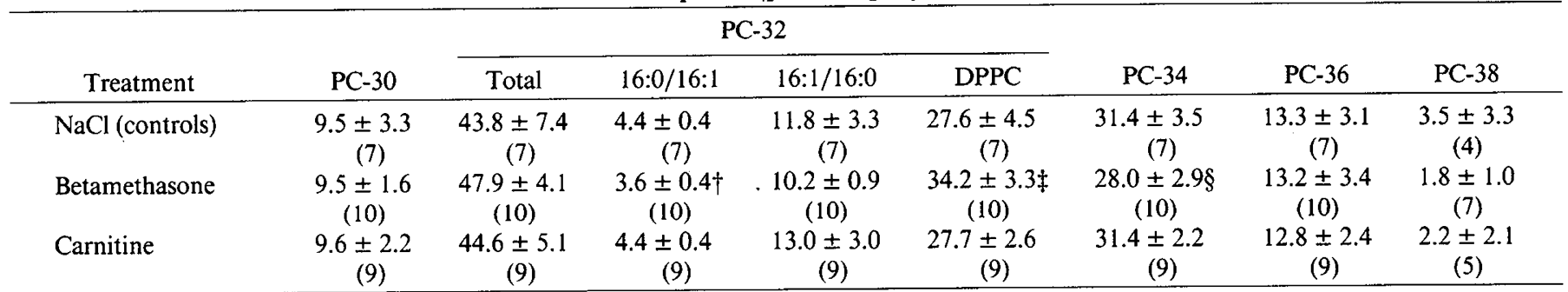

* Values are mean $\pm \mathrm{SD}$, with number of experiments in parentheses.

$\uparrow$ Significantly lower $(p<0.01)$ compared to the control and carnitine values.

$\ddagger$ Significantly higher $(p<0.01)$ compared to the control and carnitine values.

$\S$ Significantly lower $(p<0.05)$ compared to the control and carnitine values.

$(p<0.01)$ and 16:1/16:0-PC species (Fig. 3, Table 2). By contrast, the reduction of the 18:1 portion in the PC fatty acids $(p<0.05)$ corresponds to the lowering of the PC-34 portion in the PC species $(p<0.05)$ (Table 2).
Carnitine. Figure 5 shows the content of total carnitine $(A)$, free carnitine $(B)$, and short chain acylcarnitine $(C)$ in the fetal lungs. Betamethasone fails to influence the carnitine content of the fetal lungs. Despite the low carnitine dose used $(10 \mathrm{mg} / \mathrm{kg})$, 
A

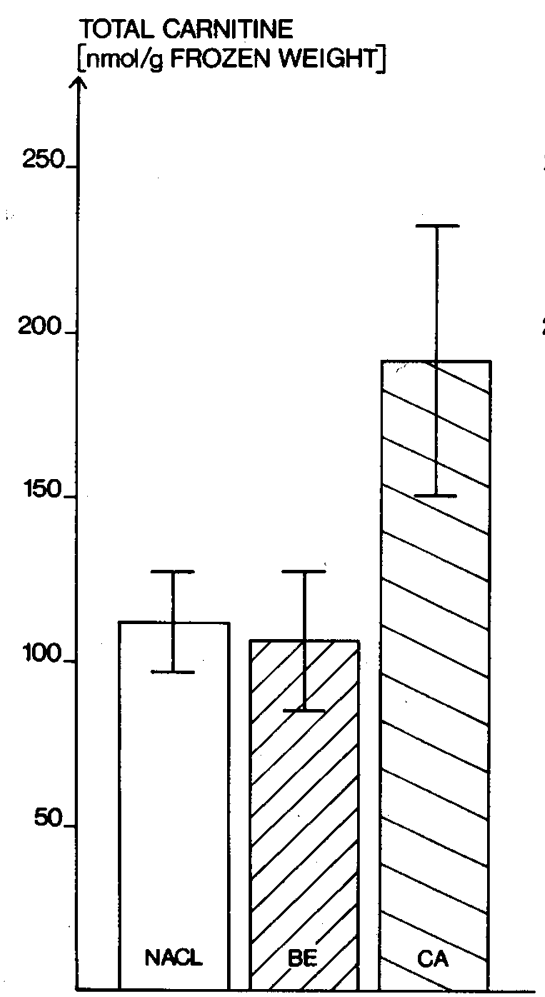

B

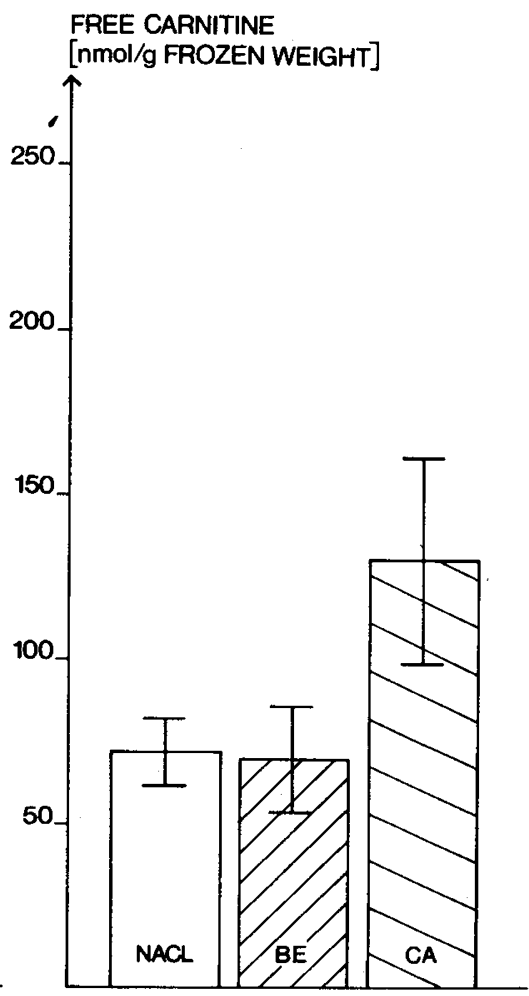

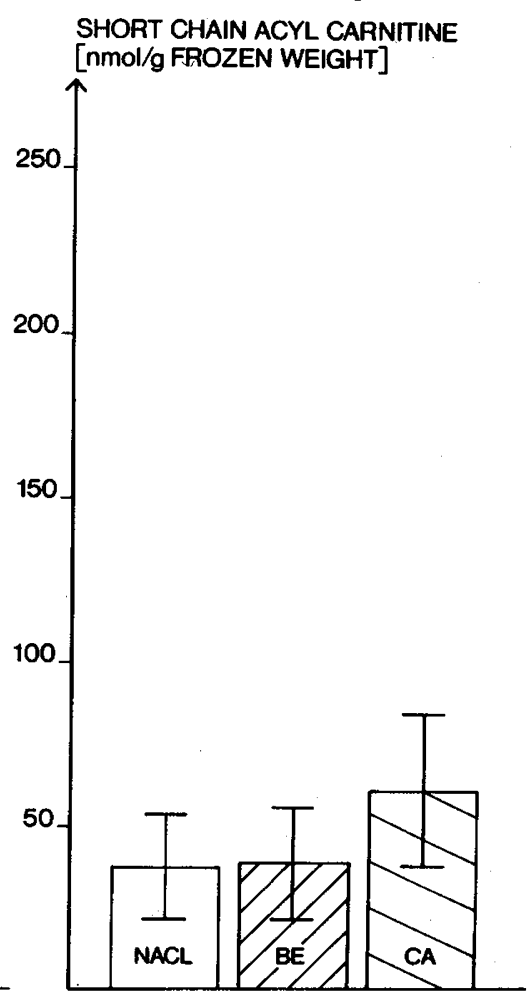

Fig. 5. L-Carnitine content (in nmol/g frozen weight) of fetal rats lungs following maternal betamethasone $(B E)(n=10)$ and L-carnitine $(C A)$ $(n=10)$ in comparison to the control group $(N A C L)(n=6)$. A shows the content of "total" carnitine (i.e. short chain acylcarnitine + free carnitine); the $C A$ value, $192 \mathrm{nmol} / \mathrm{g}$ frozen weight \pm 41 , is significantly $(p<0.01)$ higher compared to that of $B E, 106 \pm 21$, and $N A C L, 112 \pm 15, B$ shows the content of free carnitine; the $C A$ value, $130 \pm 31$, is significantly higher compared to that of $B E, 70 \pm 16$, and $N A C L, 72 \pm 10(p<0.01)$. $C$ shows the content of short chain acylcarnitine; $C A: 61 \pm 23 ; B E: 39 \pm 17$; and NACL $38 \pm 16$. Bars indicate the mean \pm SD in each group.

there is a marked increase in both free $(p<0.01)$ and short chain acylcarnitine in the fetal lungs.

\section{DISCUSSION}

Betamethasone. Anderson et al. (3) found a marked increase in the uptake of labeled choline in the PC of fetal lungs as compared to the controls only in doses of between 0.8 and 6.4 $\mathrm{mg} / \mathrm{kg}$ betamethasone (administered maternally on the 20th day of gestation). On the other hand, a dose of $0.4 \mathrm{mg}$ dexamethasone has been shown to depress DNA by $51 \%$, total PC by $28 \%$, and disaturated PC by $33 \%$ (15). In the present study, an increase in DPPC content with respect to the dry weight of the fetal lungs and a simultaneous decrease in all assayed PC species as compared to the control values was found after administration of betamethasone to the mother animals. When we compare the composition of the PC species in the fetal lungs, it is striking that the elevation of the DPPC portion in the PC species (from 27.6 to $34.2 \%$ ) was compensated for by a depression of monoenic species (Fig. 2). These findings were substantiated by determinations of the fatty acid composition (Table 1).

Of special interest regarding the differences of the PC species composition in fetal lungs and the lungs of adult animals are the two monoenic PC-32 species (16:0/16:1-PC and 16:1/16:0-PC). Whereas in the fetal lungs 16:1/16:0-PC makes up the major portion of the PC-32 monoenic fraction, in the lungs of adult male rats this PC species is only a minor constituent and 16:0/ 16:1-PC represents the dominant fraction of the PC-32 monoenic species (36). There is no notable reversal of the ratio of these two PC-32 monoenic species following betamethasone treatment, as would be expected in the case of accelerated assimilation of the PC profile of the fetal lungs to that of adult animals. On the contrary, a reduction in both absolute and relative terms of both
PC-32 monoenic species is observed. The potential importance of these two PC species for the lung function or as a predictor of fetal lung maturity has yet to be established. In addition to effecting changes in the PC species composition of fetal lungs and an accelerating choline uptake in the pulmonary PC in both in vitro and in vivo models, corticosteroids also exert an influence on protein metabolism. A marked reduction in DNA content per lung has been reported $(2,15,25)$, which points to a retardation of pulmonary mitosis, with differentiation of the lung cells being favored. Thus, morphologic changes in the fetal lungs as compared to untreated controls have been found $24-48 \mathrm{~h}$ after steroid treatment and have been interpreted as an expression of functional and morphologic maturation of the lungs $(12,27$, 37). Of special importance in this context is the proliferation of alveolar type II cells $(37,45,50)$, as well as enhanced formation of lamellated corpuscles in type II cells $(37,38,50)$. A characteristic of type II cells is the high portion of disaturated PC in the PC species $(8,33)$. If the number of type II cells increases with respect to the other lung cells, an elevation in the DPPC content, as found in the present experimental series after betamethasone treatment, should be expected. In addition, stimulation of PC synthesis in type II cells by steroids has been reported $(2,40,43)$.

$A$ reduction in the number of lung cells in addition to a possible enhancement of PC synthesis in type II cells could account for the findings of the present investigation, i.e. total phospholipid content similar to that of the controls with simultaneous elevation of the DPPC content. A direct comparison of the betamethasone-treated group with the control group could be distorted by an inhibitory effect of the steroid on protein synthesis, which, in turn, would alter the dry weight of the fetal lungs as a point of reference.

Carnitine. In the present study, it was demonstrated that the administration of L-carnitine to pregnant rats elevates the levels 
of both free carnitine and acetylcarnitine in the fetal lungs to approximately twice those of the controls and the group treated with betamethasone.

In the untreated fetal rat lungs, the carnitine and acetylcarnitine levels increase from the 19 th day of gestation up to parturition (A. Lohninger, unpublished results). A comparison of untreated with $\mathrm{L}$-carnitine-treated animals reveals that the maternal administration of a relatively low L-carnitine dose results in a carnitine level in the fetal lungs on the 20th day that is roughly equivalent to that of untreated animals on the 22 nd or 23 rd day of gestation (term). Since, however, carnitine was given only in low doses $(10 \mathrm{mg} / \mathrm{kg})$, it is highly probable that even higher Lcarnitine levels than those obtained in the present study could be attained through the administration of higher L-carnitine doses. After all, owing to its low toxicity $(47,51)$, carnitine doses of $100-150 \mathrm{mg} / \mathrm{kg}$ have already been clinically administered $(4,5)$.

In most of the tissues there is a higher carnitine concentration than in the plasma. An active transport mechanism for the uptake of L-carnitine across a high concentration gradient has been described in human heart cells $(6,9)$, in isolated liver cells $(10,11)$, and in kidney (22) and muscle cells (41) of rats. Carnitine is probably also transported across the plasma membrane of lung cells by the same or at least a similar mechanism. Moreover, it is apparent that this carrier system for the uptake of carnitine by lung cells of fetal rats is activated relatively early in the gestation period. The limiting factor for the carnitine concentration in the cells is probably the lower carnitine concentration in the fetal circulation.

Even if placental passage of carnitine in rats is lower than that in other species, e.g. guinea pigs (17), there is a demonstrable increase of both free L-carnitine and L-acetylcarnitine levels in fetal rat lungs following the maternal administration of relatively small amounts of carnitine. Hahn et al. (16) were able to show that injection of $\left[{ }^{14} \mathrm{C}\right]$ carnitine into pregnant rats resulted in the appearance of the label in amniotic fluid. It is of interest to note in this context that in man levels of both free and acetylcarnitine have been found to be higher in cord blood than in maternal blood, suggesting placental transfer to be adequate $(16,19)$. As in rabbits and guinea pigs, there is a high carnitine tissue level even before birth (18); these species are unsuitable as experimental models for studying carnitine metabolism in fetal lungs, since such findings cannot be extended to human fetal lungs.

The increase in the DPPC content following carnitine treatment could also be accounted for by the investigation of Ishidate and Weinhold (23), who found that a further important pathway of DPPC synthesis takes place via de novo synthesis of PC through utilization of dipalmitoylglycerol. With this metabolic pathway, an increase in the DPPC content of fetal lungs would be conceivable in the context of an overall rise in PC synthesis without necessarily entailing stimulation of the deacylation-reacylation cycle or the proliferation of type II cells. However, it is generally assumed that this de novo PC synthesis makes only a minor contribution to the DPPC content of the lungs $(48,49)$.

In considering the effect of carnitine treatment on the quantitative changes of various PC species in fetal lungs (Table 2), it is noteworthy that most of the assayed PC species revealed an increase as compared to the controls. In view of the similar composition of the $\mathrm{PC}$ species in the fetal lungs of the control group and those of the carnitine-treated group, an overall elevation of the phospholipid and PC content in the fetal lungs is more probable than a specific stimulation of DPPC synthesis.

The findings of the present study suggest that betamethasone and carnitine effect an elevation of the DPPC level in fetal lungs via two dissimilar mechanisms. Maternal treatment with a carnitine-betamethasone combination may therefore be more effective in increasing pulmonary surfactant production than the administration of carnitine or betamethasone alone.

Acknowledgments. The authors wish to express their appreciation to Wolfgang Riedl and Anton Piegler for their technical assistance and to Barbara Lohninger for organizational and secretarial help.

\section{REFERENCES}

1. Abdellatif MM, Hollingsworth M 1980 Effect of oxotremorine and epinephrine on lung surfactant secretion in neonatal rabbits. Pediatr Res 14:916

2. Adamson IYR, Bowden DH 1975 Reaction of cultured adult and fetal lung to prednisolone and thyroxine. Arch Pathol 99:80

3. Anderson GG, Lamden MP, Cidlowski JA, Ashikaga T 1981 Comparative pulmonary surfactant-inducing effect of three corticosteroids in the nearterm rat. Obstet Gynecol 139:562

4. Angelini C 1975 Carnitine deficiency. Lancet 2:554

5. Angelini C, Lücke S, Cantarutti F 1976 Carnitine deficiency of skeletal muscle: report of a treated case. Neurology 26:633

6. Bahl JJ, Navin TR, Bressler R 1980 Carnitine uptake and stimulation of carnitine uptake in the isolated beating adult rat heart myocyte. In: Frenkel RE, McGarry JD (eds) Carnitine Biosynthesis, Metabolism, and Functions. Academic Press Inc, New York, pp 91-113

7. Bartlett GR 1959 Phosphorus assay in column chromatography. J Biol Chem 234:466

8. Batenburg JJ, Longmore WJ, van Golde LMG 1978 The synthesis of phosphatidylcholine by adult rat lung alveolar type II epithelial cells in primary culture. Biochim Biophys Acta 529:160

9. Bøhmer T, Mølstad P 1980 Carnitine transport across the plasma membrane. In: Frenkel RE, McGarry JD (eds) Carnitine Biosynthesis, Metabolism, and Functions. Academic Press Inc, New York, pp 73-89

10. Bremer J 1977 Carnitine and its role in fatty acid metabolism. Trends Biochem Sci Sept 207

11. Christiansen RZ, Bremer J 1976 Active transport of butyrobetaine and carnitine into isolated liver cells. Biochim Biophys Acta 448:562

12. De Lemos RA, Shermeta DW, Knelson JH, Kotas R, Avery ME 1970 Acceleration of appearance of pulmonary surfactant in the fetal lamb by administration of corticosteroids. Am Rev Respir Dis 102:459

13. Folch J, Lees M, Stanley GH 1957 A simple method for the isolation and purification of the total lipids from animal tissues. J Biol Chem 226:497

14. Fritz IB 1963 Carnitine and its role in fatty acid metabolism. Adv Lipid Res $1: 285$

15. Funkhouser JD, Hughes ER 1980 Fetal lung desaturated phosphatidylcholine. Ostensible increase following exposure to dexamethasone. Biochim Biophys Acta 619:509

16. Hahn P, Skala JP, Seccombe DW, Frohlich J, Penn-Walker D, Novak M, Hynie I, Towell ME 1977 Carnitine content of blood and amniotic fluid. Pediatr Res 11:878

17. Hahn P, Seccombe D 1980 Control of blood carnitine and carnitine acyltransferases in the perinatal period. In: Frenkel RE, McGarry JD (eds) Carnitine Biosynthesis, Metabolism, and Functions. Academic Press Inc, New York, pp 177-189

18. Hahn P, Seccombe D, Towell ME 1980 Perinatal changes in plasma carnitine levels in four species of mammal. Experientia 36:1341

19. Hahn P 1982 Carnitine in the perinatal period of mammals. Nutr Res 2:201

20. Hamosh M, Hamosh P 1977 The effect of prolactin on the lecithin content of fetal rabbit lung. J Clin Invest 59:1002

21. Harbhajan SP, Adibi SA 1978 Effect of carnitine on branched chain amino acid oxidation by liver and skeletal muscle. Am J Physiol 234:E494

22. Huth PJ, Shug AL 1980 Properties of carnitine transport in rat kidney cortex slices. Biochim Biophys Acta 602:621

23. Ishidate K, Weinhold PA 1981 The content of diacylglycerol, triacylglycerol and monoacylglycerol and a comparison of the structural and metabolic heterogeneity of diacylglycerol and phosphatidylcholine during rat lung development. Biochim Biophys Acta 664:133

24. Kanjanapone V, Hartig-Beecken I, Epstein MP 1980 Effect of isoxsuprine on fetal lung surfactant in rabbits. Pediatr Res 14:278

25. Kotas V, Mims LC, Mart LK 1974 Reversible inhibition of lung cell number after glucocorticoid injection into fetal rabbits to enhance surfactant appearance. Pediatrics 53:358

26. Liggins GC 1969 Premature delivery of foetal lambs infused with glucocorticoids. J Endocrinol 45:515

27. Liggins GC, Howie RN 1972 A controlled trial of antepartum glucocorticoid treatment for prevention of the respiratory distress syndrome in premature infants. Pediatrics 50:515

28. Lipshitz J, Broyles K, Hessler JR, Whybrew WD, Ahokas RA, Anderson GD 1981 Effects of hexoprenaline on the L/S-ratio and pressure-volume relationships in fetal rabbits. Am J Obstet Gynecol 139:726

29. Lohninger A, Nikiforov A 1980 Quantitative determination of natural dipalmitoyl lecithin with dimyristoyl lecithin as internal standard by capillary gas-liquid chromatography. J Chromatogr 192:185

30. Lohninger A, Salzer H, Simbruner G, Husslein P, Martin G 1983 Relationship among human amniotic fluid dipalmitoyl lecithin, postpartal respiratory compliance and neonatal RDS. Clin Chem 29:650

31. Lopes-Cardozo M, Klazinga W, van den Bergh S 1978 Accumulation of carnitine esters of $\beta$-oxidation intermediates during palmitate oxidation by rat-liver mitochondria. Eur J Biochem 83:629

32. Markwell MAK, McGroarty EJ, Bieber LL, Tolbert NE 1973 The subcellular distribution of carnitine acyltransferases in mammalian liver and kidney. $J$ Biol Chem 248:3426

33. Mason RJ, Williams MC 1980 Phospholipid composition and ultrastructure of A549 cells and other cultured pulmonary epithelial cells of presumed type 
II cell origin. Biochim Biophys Acta 617:36

34. McGarry DJ, Foster DW 1976 An improved and simplified radioisotopic assay for the determination of free and esterified carnitine. J Lipid Res 17:277

35. Myher JJ, Kuksis A, Marai L, Yeung SKF 1978 Microdetermination of molecular species of oligo- and polyunsaturated diacylglycerols by gas chromatography-mass spectrometry of their tert-butyl dimethylsilyl ethers. Anal Chem 50:557

36. Nikiforov A, Lohninger A, Specker M, Linhart L 1982 Studies on molecular species of dog lung $s n$-glycerol-3-phosphocholines by gas liquid chromatography-mass spectrometry and computer accumulated integrated field desorption mass spectrometry (FD-CAI MS). Eur J Mass Spectrom Biochem Med Environ Res 2:105

37. Picken JJ, Lurie M, Kleinerman J 1975 Prolonged glucocorticoid treatment in the rat: effects on pulmonary morphology, ultrastructure and elastic properties. Chest $67: 48 \mathrm{~S}$

38. Possmayer F, Duwe G, Metcalfe R, Stewart-DeHaan PJ, Wong C, Heras JL, Harding PGR 1977 Cortisol induction of pulmonary maturation in the rabbit foetus: its effects on enzymes related to phospholipid biosynthesis and on marker enzymes for subcellular organelles. Biochem J 166:485

39. Possmayer F, Casola PG, Chan F, MacDonald P, Ormseth MA, Wong T, Harding PGR, Tokmakjian S 1981 Hormonal induction of pulmonary maturation in the rabbit fetus. Effects of maternal treatment with estradiol$17 \beta$ on the endogenous levels of cholinephosphate, CDP-choline and phosphatidylcholine. Biochim Biophys Acta 664:10

40. Post M, Batenburg JJ, van Golde LMG 1980 Effects of cortisol and thyroxine on phosphatidylcholine and phosphatidylglycerol synthesis by adult rat lung alveolar type II cells in primary culture. Biochim Biophys Acta 618:308

41. Rebouche CJ 1977 Carnitine movement across muscle cell membranes. Studies in isolated rat muscle. Biochim Biophys Acta 471:145
42. Rooney SA, Marino PA, Gobran LI, Gross I, Warshaw JB 1979 Thyrotropinreleasing hormone increases the amount of surfactant in lung lavage from fetal rabbits. Pediatr Res 13:623

43. Sanders RL, Engle MJ, Douglas WHJ 1981 Effect of dexamethasone upon surfactant phosphatidylcholine and phosphatidylglycerol synthesis in organotypic cultures of type II cells. Biochim Biophys Acta 664:380

44. Schönberger W, Grimm W, Emmrich P, Gempp W 1980 Thyroid administration lowers mortality in premature infants. Eur $\mathrm{J}$ Pediatr 133:181

45. Smith BT, Torday JS, Giroud CJP 1974 Evidence for different gestationdependent effects of cortisol in cultured fetal lung cells. J Clin Invest 53:1518

46. Sundell HW, Gray ME, Relier JP, Swift LL, Stahlman MT 1979 The effects of ACTH on lung maturation in fetal lambs. Am J Pathol 97:393

47. Tao RC, Yoshimura NN 1980 Carnitine metabolism and its application in parenteral nutrition. J Parenter Enter Nutr 4:469

48. Van Golde LMG 1976 Metabolism of phospholipids in the lung. Am Rev Respir Dis 114:977

49. Van Heusden GPH, Noteborn HPJM, van den Bosch H 1981 Selective utilization of palmitoyl lysophosphatidylcholine in the synthesis of disaturated phosphatidylcholine in rat lung. A combined in vitro and in vivo approach. Biochim Biophys Acta 664:49

50. Wang NS, Kotas RV, Avery ME, Thurlbeck WM 1971 Accelerated appearance of osmiophilic bodies in fetal lungs following steroid injection. J Appl Physiol 30:362

51. Wolff J, Müller DM, Strack E 1971 Toxizität von L(-)-Carnitine und einigen Acylcarnitinen. Acta Biol Med Germ 26:1237

52. Wu B, Kikkawa Y, Onzalesi MM, Motoyama EK, Kaibara M, Zigas CJ, Cook $C D 1973$ The effect of thyroxine and the maturation of fetal rabbit lungs. Biol Neonate 22:161

\title{
Food Proteins and Gut Mucosal Barrier. II. Differential Interaction of Cow's Milk Proteins with the Mucous Coat and the Surface Membrane of Adult and Immature Rat Jejunum
}

\author{
M. STERN, K. Y. PANG, AND W. A. WALKER \\ Combined Pediatric Gastrointestinal and Nutrition Division, Massachusetts General Hospital, Children's \\ Hospital, Harvard Medical School, Boston, Massachusetts 02114
}

\begin{abstract}
Two in vitro intestinal models were used to investigate postnatal maturational changes of the gut barrier functions. Microvillus membrane (MVM) preparations were studied for surface binding, and everted gut sacs were studied for mucous coat binding, breakdown and uptake of radioiodinated bovine serum albumin (BSA), and $\beta$-lactoglobulin ( $\beta$-LG). Surface binding of these proteins to MVM was weak and nonspecific. There was more binding of both proteins to immature MVM (BSA: newborns, $2.74 \pm 0.52 \%$, adults, $1.08 \pm 0.17 \%, p<0.001 ; \beta$ LG: newborns, $6.30 \pm 0.54 \%$; adults, $2.05 \pm 0.07, p<$ 0.001 ). In contrast to MVM binding characteristics, mu-
\end{abstract}

Received February 1, 1984; accepted May 22, 1984.

Requests for reprints may be addressed to Dr. Martin Stern, UniversitaetsKinderklinik. Martinistrasse 52, D-2000 Hamburg 20, Federal Republic of Germany.

This work was supported by grants from Deutsche Forschungsgemeinschaft (DFG Ste 305/2-1) and from the National Institutes of Health (AM 16269, GM 21700 , and HD 12437). cous coat binding of the cow's milk proteins to immature gut sacs was significantly less (BSA: preweanlings, $0.94 \pm$ $0.30 \mu \mathrm{g}{ }^{125}$-I-protein $\mathrm{Eq} / \mathrm{mg}$ mucosal protein; adults, 3.06 $\pm 0.74, p<0.001 ; \beta$-LG: preweanlings, $5.61 \pm 1.48$; adults, $9.83 \pm 1.33, p<0.001)$. Protein binding and uptake were correlated in the immature animals $(r=0.76, p<0.001$ for BSA and $r=0.85, p<0.001$ for $\beta$-LG). More $\beta$-LG was bound and taken up than BSA in the preweanlings ( $p$ $<0.001$ ). Trichloroacetic acid precipitation studies showed that, even in the immature rats, $\beta-L G$ was much more readily broken down by mucosa-associated enzymes than BSA. Immature animals showed less protein breakdown than adult controls. Decreased protein breakdown and mucous coat binding as well as increased MVM binding may account for the increased uptake of intact food antigens in the newborn. Differences between increased MVM binding and decreased mucous coat binding of cow's milk proteins are attributed to protective elements such as the mucus layer which is present in the gut sac model but lacking in MVM. (Pediatr Res 18:1252-1256, 1984) 